\title{
Radical scavenging activity of an inulin-gallic acid graft and its prebiotic effect on Lactobacillus acidophilus in vitro growth
}

\author{
Daniel Arizmendi-Cotero ${ }^{a}$, Adriana Villanueva-Carvajal ${ }^{a}$, Rosa María Gómez-Espinoza ${ }^{\text {}}$, \\ Octavio Dublán-García ${ }^{\mathrm{c}}$, Aurelio Dominguez-Lopez ${ }^{\mathrm{a}, *}$ \\ a Facultad de Ciencias Agrícolas, Universidad Autónoma del Estado de México, Campus Universitario “El Cerrillo”, km 15, Carr. Toluca-Ixtlahuaca, Entronque El Cerrillo, \\ Apdo. Postal 435, Toluca 50200, Estado de México, Mexico

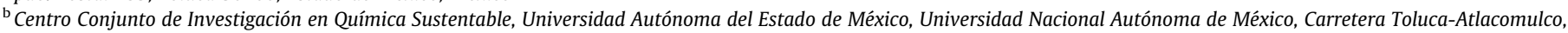 \\ km 14.5, 50200 Toluca, Estado de México, Mexico \\ ${ }^{c}$ Facultad de Química, Universidad Autónoma del Estado de México, Avenida Paseo Tollocan S/N, Toluca 50180, Estado de México, Mexico
}

\section{A R T I C L E I N F O}

Article history:

Received 24 May 2016

Received in revised form 24 November 2016

Accepted 9 December 2016

\section{Keywords:}

Inulin

Molecular grafting

Prebiotics

Radical scavenging activity

\begin{abstract}
A B S T R A C T
In order to generate a new antioxidant and prebiotic dietary fibre, gallic acid (GA) was grafted onto native inulin. Inulin-gallic acid (IGA) graft was confirmed by UV and infrared spectroscopy (FT-IR). The antioxidant activity was evaluated by spectroscopic methods and the prebiotic activity of IGA was determined by In-Vitro growth of Lactobacillus acidophilus. UV spectra show absorbance peaks at 214 and 266-268 nm showing aromatic ring presence in the IGA graft and FT-IR spectra showed a band at $1743 \mathrm{~cm}^{-1}$, confirming the covalent bond between the polymer and GA. GA provides a significant antioxidant capacity to IGA graft. Inulin shows a significant capacity to stimulate the growth of L. acidophilus and GA grafted onto inulin $(16.3 \mathrm{mg} / \mathrm{g}$ polymer) does not interfere with its prebiotic capacity. It is possible to provide radicalscavenging capacity to inulin-type fructo-oligosaccharides avoiding the decrease of its prebiotic properties, which could extend their potential use as functional foods.
\end{abstract}

(c) 2016 Elsevier Ltd. All rights reserved.

\section{Introduction}

Dietary fibre contained in some vegetable food products can be associated with phenolic compounds and therefore exhibits a significant antioxidant activity (Saura-Calixto, Pérez-Jiménez, \& Goñi, 2009). This kind of fibre is known as antioxidant dietary fibre (ADF) and because of its polymer structure it could show a considerable prebiotic capacity as well. Some studies have suggested that polyphenols associated with this dietary fibre could be released in the gastrointestinal tract during digestion (Mercado-Mercado et al., 2015). Hence, besides its prebiotic activity ADF could increase the radical scavenging activity of the human gut environment.

Recent research has been directed to the synthesis of ADF through the molecular grafting of polymeric materials such as phenolic derivatives onto several biopolymers. Molecular grafting is a polymeric material modification method involving reactions that

\footnotetext{
* Corresponding author.

E-mail addresses: arcoda21@gmail.com (D. Arizmendi-Cotero), adrcarvajal@ gmail.com (A. Villanueva-Carvajal), rosamarigo@gmail.com (R.M. Gómez-Espinoza), octavio_dublan@yahoo.com.mx (O. Dublán-García), adominguezl@uaemex.mx (A. Dominguez-Lopez).
}

require a reductive compound as initiator generating a free radical, par example ascorbic acid/hydrogen peroxide $\left(\mathrm{AA} / \mathrm{H}_{2} \mathrm{O}_{2}\right)$ redox pair (Cirillo et al., 2010; Curcio et al., 2009; Spizzirri et al., 2009, 2011). The hydroxyl radical $(. \mathrm{OH})$ that initiates the reaction is formed when $\mathrm{H}_{2} \mathrm{O}_{2}$ oxidizes AA. After that, the grafting process of the molecule takes place in two steps. The first one consists in generating a macro-radical in the biopolymer chain through the reaction with the free radical obtained between $\mathrm{AA}$ and $\mathrm{H}_{2} \mathrm{O}_{2}$. In the second step, the antioxidant molecule links to the recently formed macroradical through a covalent bond (Curcio et al., 2009; Spizzirri et al., 2009, 2010; Toti \& Aminabhavi, 2004). In the last years several phenolic compounds-biopolymers grafted conjugates with diverse food applications related to their antioxidant activity have been studied: catechin-alginate and catechin-inulin (Spizzirri et al., 2010); gallic acid-chitosans (Cho, Kim, Ahn, \& Je, 2011; Woranuch, Yoksan, \& Akashi, 2015), gallic acid and catechingelatin (Cirillo et al., 2010; Spizzirri et al., 2009), etc. Since some of these biopolymers, prior to being grafted, have significant prebiotic activity, the novel conjugates could have a potential use as prebiotic and antioxidant compounds (Arizmendi-Cotero, GómezEspinosa, García, Gómez-Vidales, \& Dominguez-Lopez, 2016).

According to Saura-Calixto (2011) around 50\% of the total dietary antioxidants, mainly phenolics pass through the small intestine 
linked to dietary fibre. They are released from the fibre matrix in the colon by the action of the bacterial microbiota, producing metabolites and an antioxidant environment. Consequently the transportation of dietary antioxidants through the gastrointestinal tract may be an essential function of dietary fibre. However, in food (particularly vegetables), both dietary fibre and antioxidant compounds are a complex group of substances with a wide range of molecular mass. The inulin-gallic acid conjugate synthesized by Arizmendi-Cotero et al. (2016) or those obtained by others (Liu, Wen, Lu, Kan, \& Jin, 2014; Zhang, Geng, Jiang, Li, \& Huang, 2012) could be a suitable and relatively simple model to study the antioxidant and prebiotic effect of dietary fibre naturally associated with polyphenols. Thus, the goals of this study were (i) to measure the antioxidant activity of an inulin-gallic acid conjugate obtained by molecular grafting and (ii) to evaluate the conjugate's in vitro prebiotic capacity on a Lactobacillus acidophilus culture.

\section{Materials and methods}

\subsection{Materials}

Native inulin (inulin) was purchased from Frutafit (IQ VA Mexico S.A. C.V.); Hydrogen peroxide $\left(\mathrm{H}_{2} \mathrm{O}_{2}\right)$, ascorbic acid (AA), gallic acid (GA), pyrogallol, Folin-Ciocalteau's reagent, 2,2-diphenyl-1picrylhydrazyl (DPPH), 2,2,6,6-tetra-methylpiperidine (TEMP, 99\%), 2,2,6,6-tetramethylpiperidine-1-oxil (TEMPO, 99\%) and hematoporphyrin (HP, 50\%) were purchased from Sigma-Aldrich (Sigma Chemical Co., St. Louis, MO, USA); 5,5-di-methyl-1pyrroline-1-oxide (DMPO, ultra-high purity) was purchased from Dojindo; 2-tiobarbituric acid (TBA, 99\%) from ICN Biomedical, Inc. (Ohio); trichloro acetic acid (TCA, 99\%) from Fulka; iron (II) sulfate heptahydrate (99\%), ethylenediaminetetraacetic acid disodium salt dehydrate (EDTA, 98.5\%) from Sigma Chemical Co.; ethyl alcohol absolute (99.95\%) from J.T. Baker; and deionized water.

\subsection{Equipment}

Electron Paramagnetic Resonance Spectroscopy (EPR) determinations were conducted in an EPR spectrometer (Jeol JES-TE300), operated at X-Band fashions at $100 \mathrm{kHz}$ modulation frequency with a cylindrical cavity (TE011 mode). Individual samples were placed in a quartz flat cell (synthetic quartz, Wilmad Glass Company) with a path length of $0.2 \mathrm{~mm}$. The external calibration of the magnetic field was conducted using a JEOL ES-FC5 precision gauss-meter. The acquisition and manipulation of spectra were performed using the ES-IPRIT/TE program. In order to characterize the grafted molecules, the following assays were conducted: Fourier Transformed Infrared Spectroscopy (FT-IR) which were obtained using a Perkin-Elmer ATR-FT-IR; UV-Vis spectra which were performed in a Genesys, 10 UV Scanning Spectrometer (Thermo Spectronic, NY, USA).

\subsection{Inulin-gallic acid grafts' synthesis}

Inulin-gallic acid (IGA) conjugates' synthesis, using $\mathrm{H}_{2} \mathrm{O}_{2} / \mathrm{AA}$ as the grafting initiator redox pair, took place according to ArizmendiCotero et al. (2016) with some modifications. A sample of $0.8 \mathrm{~g}$ of inulin was dissolved in $10 \mathrm{~mL}$ of deionized water in a reaction flask. Subsequently, $0.05 \mathrm{~g}$ of gallic acid and $1 \mathrm{~mL}$ of the initiator redox pair (5.88 $\mathrm{M} \mathrm{H}_{2} \mathrm{O}_{2} / 0.68 \mathrm{M} \mathrm{AA}$ ) was added. Samples were incubated at $25{ }^{\circ} \mathrm{C}$ for $24 \mathrm{~h}$ with constant stirring. Inulin samples were dialyzed in distilled water using a 3500 Da membrane during $48 \mathrm{~h}$ in order to eliminate the non-reacting gallic acid. IGA conjugates were lyophilized and kept in the freezer for further analysis. Inulin control sample was prepared in the same conditions but in the absence of gallic-acid. The three samples (IGA, Inulin and GA) were characterized via UV-Vis and FTIR to make sure that gallic acidinulin grafting was successful.

\subsection{Antioxidant activity of inulin-gallic acid grafts}

\subsubsection{DPPH radical-scavenging assay by EPR spin-trap}

$\mathrm{DPPH}$ radical scavenging activity was measured using the method described by Gómez-Vidales, Granados-Oliveros, NietoCamacho, Reyes-Solís, and Jiménez-Estrada (2014). In all cases, the liquid medium used was a mixture of ethanol-water $(85: 15$ $\mathrm{v} / \mathrm{v}) .200 \mu \mathrm{L}$ of Inulin and IGA graft solutions at a concentration of $18,31,56,100,178$ and $317 \mu \mathrm{g} / \mathrm{mL}$ and GA solutions at 0.10 , $0.18,0.31,0.56,1.00,1.78,3.16,5.62 \mu \mathrm{g} / \mathrm{mL}$ were mixed with $100 \mu \mathrm{LPPH}$ solution (DPPH $0.3 \mathrm{mM}$ ). Each mixture was held at $37^{\circ} \mathrm{C}$ for 15 min before collecting EPR spectra. Individual samples were placed in the quartz flat cell of the EPR-spectrometer. Measurement conditions were as follows: central field, $3550 \pm 40 \mathrm{G}$; modulation frequency, $100 \mathrm{kHz}$; modulation amplitude, $2500 \mathrm{G}$; microwave power, $8 \mathrm{~mW}$ and sweep time $2 \mathrm{~min}$. Relative percentage of DPPH scavenging capacity was calculated according to the following equation where $\mathrm{H}_{\mathrm{c}}$ and $\mathrm{H}_{0}$ are the middle peak's heights (DPPH spectrum) with and without antioxidants, respectively:

Scavenging capacity $=\left(\mathrm{H}_{0}-\mathrm{H}_{\mathrm{c}}\right) / \mathrm{H}_{0} * 100$

\subsection{2. ${ }^{1} \mathrm{O}_{2}$ formation and scavenging capacity by EPR spin-trap}

Singlet oxygen's $\left({ }^{1} \mathrm{O}_{2}\right)$ measurement was performed in order to determine the role of IGA graft and GA as scavengers. The method, reported by Gómez-Vidales et al. (2014) is briefly described as follows: the ${ }^{1} \mathrm{O}_{2}$ oxygen intermediate was generated in presence of hematoporphyrin (a photosensitizer) under visible light irradiation: a sample of hematoporphyrin (HP) in an air-equilibrated ethanol-water $(85: 15 \mathrm{v} / \mathrm{v})$ solution $(10.7 \mathrm{mM})$ and in the presence of TEMP (30 mM) was irradiated for up to 10 min with $\lambda>400 \mathrm{~nm}$, generating a TEMPO signal in the EPR spectrometer. Immediately, samples of GA and IGA $(10,100$ and $317 \mu \mathrm{g} / \mathrm{mL})$ in an airequilibrated ethanol-water $(85: 15 \mathrm{v} / \mathrm{v})$ solution with an amount of TEMP $(30 \mathrm{mM})$ were irradiated for up to $20 \mathrm{~min}$ with UV-Vis light $(\lambda>400 \mathrm{~nm})$, generating a TEMPO signal that indicated the photo-production of ${ }^{1} \mathrm{O}_{2}$. To determine the inhibition of ${ }^{1} \mathrm{O}_{2}$, the drop of the peak-height central peak of TEMPO was measured. EPR parameters were as follows: center field, $3345 \pm 40 \mathrm{G}$; microwave frequency, $9.43 \mathrm{GHz}$; modulation width, $7.9 \pm 1 \mathrm{G}$; time constant, $0.1 \mathrm{~s}$; amplitude, 200. In each case, EPR parameters were held constant, as it also was the concentration of TEMP; samples were irradiated directly within the EPR cavity.

\subsubsection{Inhibition effect of lipid peroxidation}

The lipid peroxidation (LP) inhibition effect was determined by the method described by Granados-Oliveros et al. (2013). Using an ice bath, $375 \mu \mathrm{L}$ of the protein solution $(2.66 \mathrm{mg}$ protein $/ \mathrm{mL}$ ) and $50 \mu \mathrm{L}$ of $20 \mu \mathrm{M}$ EDTA were mixed in $1.5 \mathrm{~mL}$ microtubes. Then, $25 \mu \mathrm{L}$ of GA, IGA and Inulin at adjusted concentrations to obtain final concentrations of 1,10 and $100 \mu \mathrm{g} / \mathrm{mL}$ were added to the microtubes. Samples were incubated during $30 \mathrm{~min}$ at $37^{\circ} \mathrm{C}$, after that, $50 \mu \mathrm{L}$ of $100 \mu \mathrm{M} \mathrm{FeSO}_{4}$ were added and incubated at the same temperature for $60 \mathrm{~min}$ more. Control experiments to test the induction of LP were conducted in the presence of (i) protein solution (2.66 mg protein $/ \mathrm{mL}$ ) and (ii) $\mathrm{FeSO}_{4}(10 \mu \mathrm{M})$. In order to measure lipid peroxidation, $0.5 \mathrm{~mL}$ of TBA reagent $(1 \% \mathrm{w} / \mathrm{v}$ TBA in $0.05 \mathrm{~N} \mathrm{NaOH}$ mixed with $30 \% \mathrm{w} / \mathrm{v}$ TCA in a $1: 1$ proportion) was added to each microtube. The tubes were cooled on ice for $10 \mathrm{~min}$, centrifuged at $13,000 \mathrm{~g}$ for $5 \mathrm{~min}$, and finally heated at $95{ }^{\circ} \mathrm{C}$ for $30 \mathrm{~min}$. The tubes were allowed to reach ambient temperature and finally $200 \mu \mathrm{L}$ of the supernatant solution were sepa- 
rated for analysis. The content of TBARS in all solutions was determined by optical density at $\lambda=540 \mathrm{~nm}$ using a Bio-Tek ELx 808 microplate reader.

\subsection{In vitro prebiotic effect of the IGA conjugates}

In order to determine the prebiotic effect of the IGA conjugates, MRS carbohydrate-free broth was used, according to Adebola, Corcoran, and Morgan (2014). Briefly, the media contained the following components $(\mathrm{g} / \mathrm{L})$ : peptone $(10.0)$, yeast $(5.0)$, $\mathrm{Na}$ acetate $3 \mathrm{H}_{2} \mathrm{O}(5.0), \mathrm{K}_{2} \mathrm{HPO}_{4} \cdot 3 \mathrm{H}_{2} \mathrm{O}(2.0),\left(\mathrm{NH}_{4}\right)_{3} \mathrm{C}_{6} \mathrm{H}_{5} \mathrm{O}_{7} \cdot 2 \mathrm{H}_{2} \mathrm{O}(2.0)$, $\mathrm{MgSO}_{4} \cdot 7 \mathrm{H}_{2} \mathrm{O}(0.2), \mathrm{MnSO}_{4} \cdot 4 \mathrm{H}_{2} \mathrm{O}(0.05)$ and Tween $80(1 \mathrm{~mL})$. The $\mathrm{pH}$ was adjusted to 6.2 , and the medium was sterilized at $121^{\circ} \mathrm{C}$ for $15 \mathrm{~min}$. Glucose (MRS-G), native inulin (MRS-Inulin) and IGA (MRS-IGA) were added up to final concentrations of $1 \%$ each. This concentration is recommended as the minimum to ensure the stimulating effect of a carbohydrate on the growth of bacteria on a basal MRS medium (Rubel, Pérez, Genovese, \& Manrique, 2014). A negative control deprived of a carbon source was included as well.

Lactobacillus acidophilus (LA) were incubated in MRS broth for $24 \mathrm{~h}$ and these cultures were used as starters in subsequent fermentations, according to the methodology proposed by Corral, Valdivieso-Ugarte, Ferna, Adrio, and Velasco (2008). Cells were collected by centrifugation, and suspended in sterile distilled water. Bottles containing $95 \mathrm{~mL}$ of MRS-G, MRS-Inulin and MRS-IGA medium were inoculated with $5 \mathrm{~mL}$ of each cell suspension. Then, each culture was distributed in several aliquots of $10 \mathrm{~mL}$, using sterile tubes, and incubated at $37{ }^{\circ} \mathrm{C}$. The $\mathrm{OD}_{600}$ was taken every $3 \mathrm{~h}$ or $5 \mathrm{~h}$, each tube was centrifuged at $1610 \mathrm{~g}$ during $15 \mathrm{~min}$. The precipitate was suspended in $10 \mathrm{~mL}$ of distilled water and the $\mathrm{pH}$ was also recorded as an indirect parameter of growth and sugar metabolism. All measurements were performed in triplicate in two independent experiments.

\section{Results and discussion}

\subsection{Inulin-gallic acid conjugate characterization}

\subsubsection{UV spectra}

Fig. 1 shows the UV spectra of gallic acid, pyrogallol and the inulin-gallic acid conjugate (IGA) where baseline corresponds to the previously dissolved in water unmodified inulin. The UV spectra of aromatic hydrocarbons, such as gallic acid and pyrogallol, are characterized by three peaks with origin in the $\pi \rightarrow \pi^{*}$ transitions

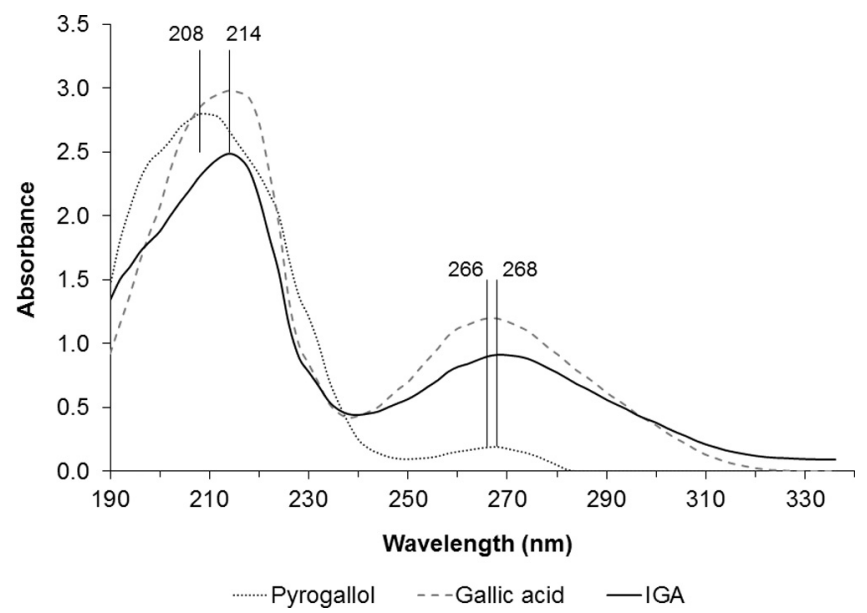

Fig. 1. UV spectrum of gallic acid, pyrogallol and inulin-gallic acid conjugate (IGA).
(Liu, Lu, Kan, \& Jin, 2013). The aromatic ring is a chromophore which has three maximum absorbances at wavelengths neighbouring 184 (not shown), 204 and $256 \mathrm{~nm}$. Hydroxyl groups $(-\mathrm{OH})$ have an auxochromic effect on this chromophore, particularly on the peak at $256 \mathrm{~nm}$, and their presence causes a displacement of these peaks toward longer wavelengths (bathochromic effect). Therefore, in the case of gallic acid and pyrogallol they were 208-214 and 266-268 $\mathrm{nm}$ by effect of the three hydroxyl groups bonded to these compounds. The spectrum of the Inulin-gallic acid conjugate was similar to aromatic hydrocarbons which suggest that the grafting was done between gallic acid's carboxylic group and inulin (200-210 nm) (Cirillo et al., 2010; Spizzirri et al., 2009).

\subsubsection{FT-IR spectra}

FT-IR analysis (Fig. 2) was performed to characterize the IGA conjugate, unmodified inulin and gallic acid. Unmodified Inulin spectrum shows typical carbohydrate bands at 950 and $1100 \mathrm{~cm}^{-1}$ related to stretching vibrations of $\mathrm{C}-\mathrm{C}$ and $\mathrm{C}-\mathrm{O}$ bonds. Besides, it shows at 2800 and $3000 \mathrm{~cm}^{-1}$ bands related to stretching vibrations of $\mathrm{C}-\mathrm{H}$ and $\mathrm{CH}_{2}$ and at 1425 and $1475 \mathrm{~cm}^{-1}$ related to the torsion of $\mathrm{C}-\mathrm{H}$ of $\mathrm{CH}_{2} / \mathrm{CH}_{3}$ groups of the alkenes. Grube, Bekers, Upite, and Kaminska (2002), found similar values in native inulin samples with different polymerization rates. GA shows bands at 1500 and $1600 \mathrm{~cm}^{-1}$ associated to the substitutions on the aromatic ring. Moreover, it shows a signal at 1720 and $1760 \mathrm{~cm}^{-1}$ linked to the stretching of $\mathrm{C}=\mathrm{O}$ of the carbonyl group. Gallic acid-polymer conjugates show new bands at 1800 and $1600 \mathrm{~cm}^{-1}$. The signal at 1760 and $1720 \mathrm{~cm}^{-1}$ corresponds to the $\mathrm{C}=\mathrm{O}$ vibration of the carbonyl group in esters. This supports the hypothesis that the covalent bond between the GA and the inulin is an ester. It is important to notice that those new peaks are not visible in the control polymer, suggesting that the inulin has been efficiently grafted (as an ester link). Similar results have been reported by Liu, Wen et al. (2014), Cirillo et al. (2010), and Spizzirri et al. (2010).

\subsection{Antioxidant activity of IGA graft}

\subsubsection{DPPH radical-scavenging assay by EPR spin-trap}

$\mathrm{DPPH}$ is a relatively stable free radical and its use in the EPR spectroscopy is a valuable and practical approach to evaluate the antioxidant potential of grafted polymer molecular fractions of antioxidants (Pasanphan, Buettner, \& Chirachanchai, 2010; Pasanphan \& Chirachanchai, 2008). IGA's DPPH radical scavenging activity was investigated through the reduction of EPR's signal spectra and the relative percent of DPPH scavenging capacity was calculated according to Eq. (1). Inulin and GA were used as negative and positive controls, respectively. Fig. 3a shows DPPH's EPR spectrum and the resulting spectra of this radical in the presence of GA and IGA graft. The inhibition of the signal's intensity caused by GA and IGA graft is evident as the wave amplitude of the radical spectra decreased significantly until it has almost been extinguished. Both GA and IGA graft showed a significant capacity to reduce DPPH radical as a function of their concentration in the liquid medium. As showed in Fig. 3b, GA exhibited the greatest activity to scavenge DPPH radical because the concentration required to reduce by $50 \%$ the signal amplitude $\left(\mathrm{IC}_{50}\right)$ was $0.72 \pm 0.05 \mu \mathrm{g} / \mathrm{mL}$ in contrast to the IGA graft which had a mean value of $77.5 \pm 10.6 \mu \mathrm{g} / \mathrm{mL}$.

Table 1 shows the concentration of GA, IGA graft and inulin at which the highest DPPH signal inhibition was achieved, where inulin reflects a nonsignificant inhibition of DPPH radical (7.48\%). Some oligosaccharides associated with fructans have a considerable capacity to reduce DPPH depending on its concentration in the liquid medium (Je, Park, \& Kim, 2004; Yang, Prasad, Xie, Lin, \& Jiang, 2011; Zhong, Lin, Wang, \& Zhou, 2012). However, when 


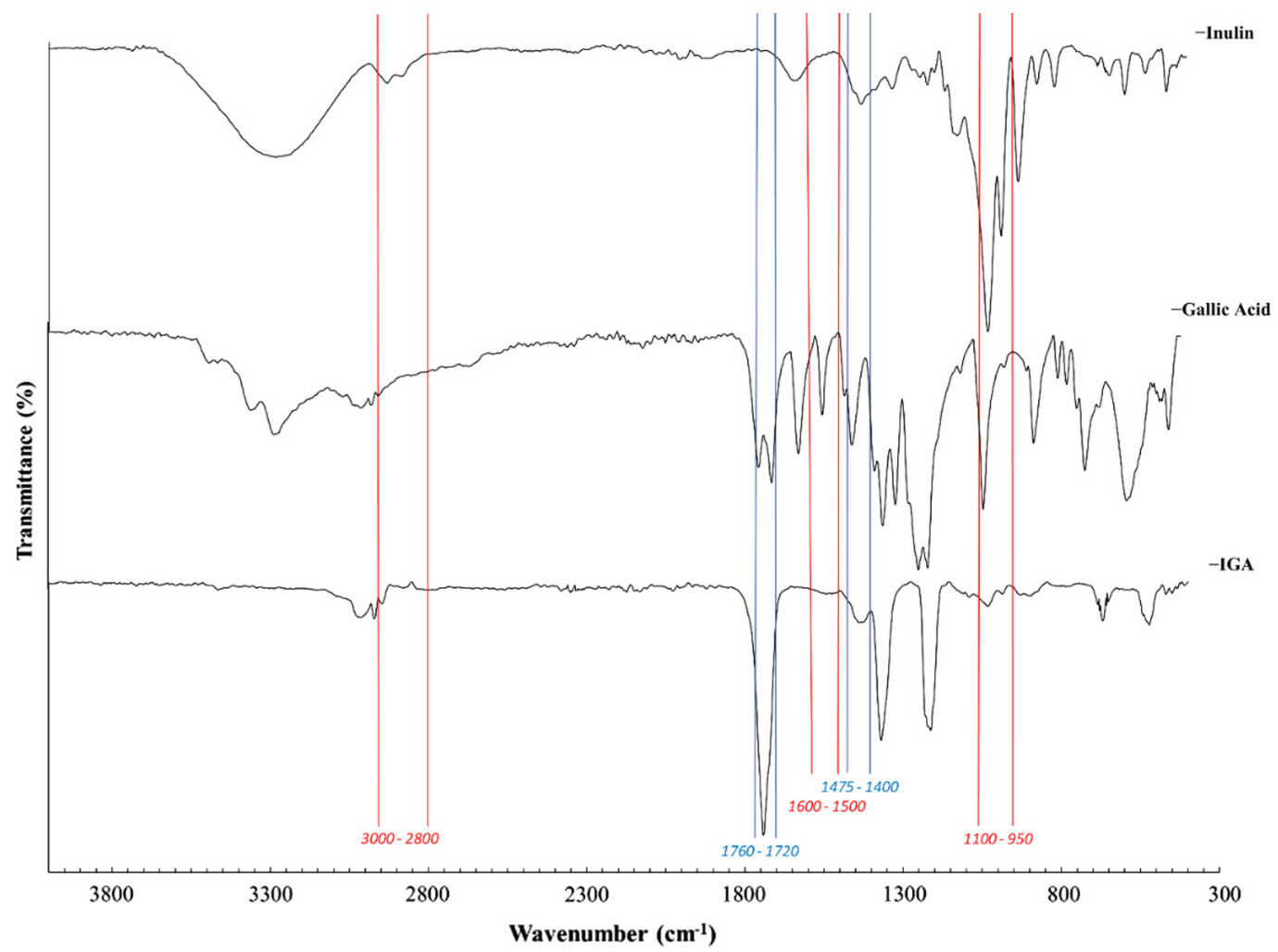

Fig. 2. FT-IR spectra for gallic acid (GA), native inulin (Inulin) and inulin-gallic acid conjugate (IGA).

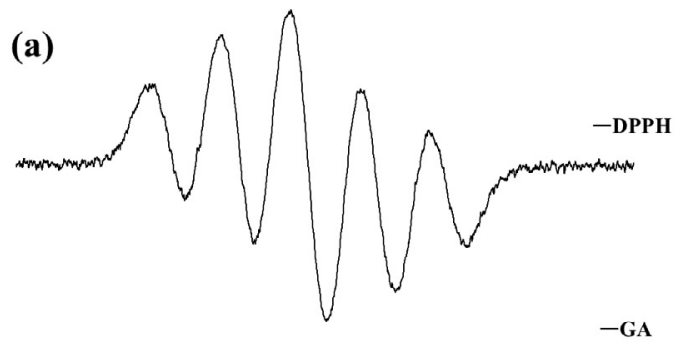

(b)
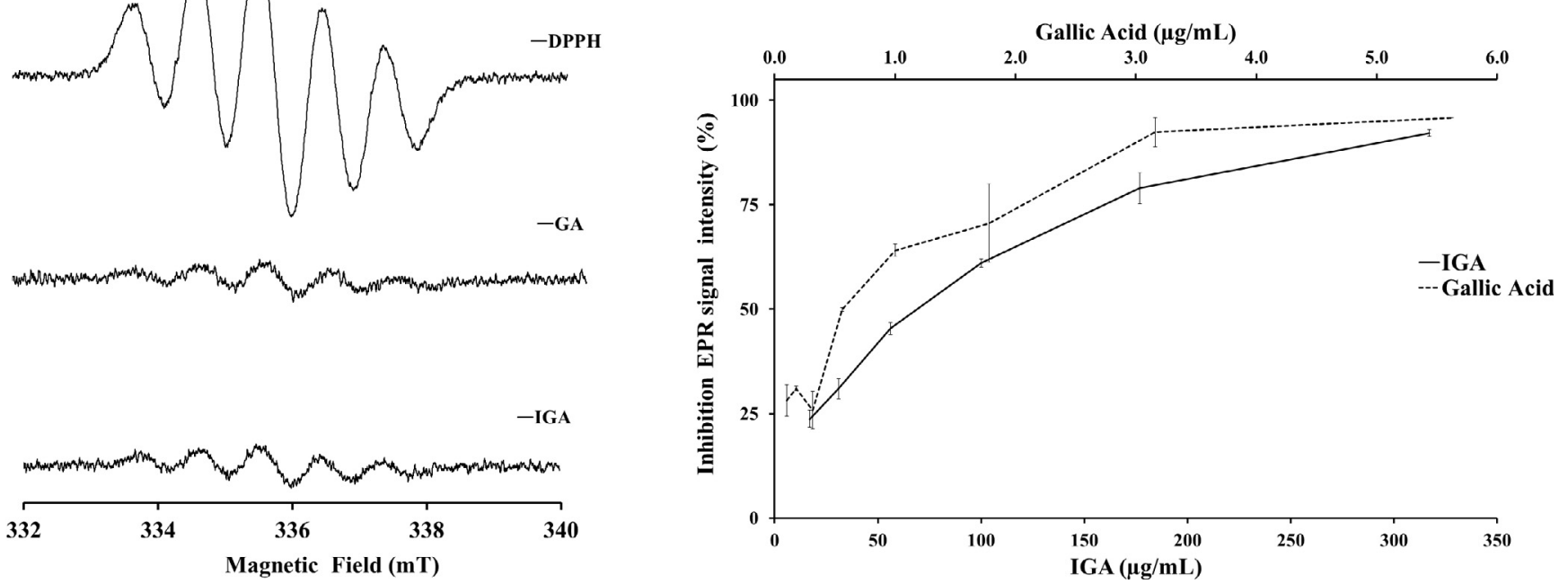

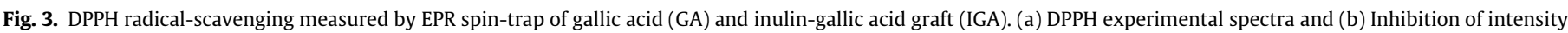
of DPPH-signal]. ${ }^{1} \mathrm{O}_{2}$ scavenging [(c) TEMP experimental spectra and (d) Inhibition of intensity of TEMP-signal].

the molecular weight of these oligosaccharides increases, its capacity to reduce DPPH decreases (Je et al., 2004; Park, Je, \& Kim, 2003). This may explain the nonsignificant DPPH radical inhibition of Inulin $(\mathrm{MW}>3 \mathrm{kDa})$.

Grafting antioxidant molecules onto the backbone of oligosaccharides gives to the new polymer a significant antioxidant capacity (Liu, Lu, Kan, Jin et al., 2013; Liu, Lu, Kan, Tang, \& Jin, 2013; Liu, Lu, Kan, Wen, \& Jin, 2014; Pasanphan et al., 2010), likewise GA grafted onto inulin acquires the capacity to scavenge DPPH radical. Table 1 shows $92.2 \%$ of DPPH's radical inhibition at $1.63 \mu \mathrm{g} / 100 \mu \mathrm{g}$ of GA grafted onto inulin backbone (5.2 g gallic acid onto $317 \mathrm{~g}$ of inulin), compared to $95.8 \%$ of inhibition of $5.6 \mathrm{~g}$ of gallic acid in its pure state. Grafting of other molecules have successfully showed antioxidant activity (Table 2) coinciding with the results showed in the present study.

\subsection{2. ${ }^{1} \mathrm{O}_{2}$ scavenging effect by EPR spin-trap}

${ }^{1} \mathrm{O}_{2}$ is generated within cells by exposure to light. This radical compound can induce oxidative damage of lipids, amino acids and nucleic acids (Gómez-Vidales et al., 2014). An EPR's inhibition 
Table 1

Antioxidant activity of gallic acid, IGA graft and inulin samples.

\begin{tabular}{|c|c|c|c|c|}
\hline Sample & Radical & Concentration $(\mu \mathrm{g} / \mathrm{mL})$ & GA equivalents $(\mu \mathrm{g})$ & Inhibition of the radical signal (\%) \\
\hline \multirow[t]{3}{*}{ Gallic Acid } & DPPH & 5.6 & 5.60 & $95.8 \pm 0.02^{\mathrm{a}}$ \\
\hline & ${ }^{1} \mathrm{O}_{2}$ & 10 & 10.00 & $32.3 \pm 0.80^{\mathrm{b}}$ \\
\hline & TBARS & 1 & 1.00 & $19.0 \pm 1.40$ \\
\hline \multirow[t]{3}{*}{ IGA } & DPPH & 317 & 5.20 & $92.2 \pm 0.92$ \\
\hline & ${ }^{1} \mathrm{O}_{2}$ & 317 & 5.20 & $29.8 \pm 1.30$ \\
\hline & TBARS & 100 & 1.63 & $19.6 \pm 0.70$ \\
\hline \multirow[t]{3}{*}{ Inulin } & DPPH & 317 & 0.00 & $7.48 \pm 2.90$ \\
\hline & ${ }^{1} \mathrm{O}_{2}$ & 317 & 0.00 & $0.00^{c}$ \\
\hline & TBARS & 100 & 0.00 & $-0.76 \pm 1.80$ \\
\hline
\end{tabular}

a Mean values \pm standard deviation of three replicates.

besults after eight minutes of irradiation.

c No activity.

Table 2

Inhibition of the DPPH signal as a function of the concentration according to the data of several authors.

\begin{tabular}{lll}
\hline Authors & $\begin{array}{l}\text { Inhibition of the } \\
\text { radical signal }(\%)\end{array}$ & $\begin{array}{l}\text { Polymer concentration } \\
(\mu \mathrm{g} / \mathrm{mL})\end{array}$ \\
\hline Spizzirri et al. (2010) & 74.0 & 2500 \\
Spizzirri et al. (2011) & 80.0 & 2500 \\
Curcio et al. (2009) & 92.0 & 2000 \\
Pasanphan et al. (2010) & 87.0 & 230 \\
Liu, Lu, Kan, Tang et al. (2013) & 74.5 & 30 \\
Cho et al. (2011) & 92.3 & 50 \\
\hline
\end{tabular}

intensity signal-time curve was obtained (Fig. 4) and results are expressed as the percentage of EPR's inhibition signal of the irradiated TEMP solution. Fig. 4a shows TEMP's EPR spectrum and the resulting spectra of this radical in the presence of GA and IGA. The signal's inhibition intensity caused by GA and IGA graft is evident as the wave amplitude of the radical spectrum decreased. GA and to a lesser extent IGA graft showed a significant capacity to reduce TEMP radical depending on their concentration in the liquid medium and on the irradiation time. After 5 and $8 \mathrm{~min}$ of irradiation, GA $(100 \mu \mathrm{g} / \mathrm{mL})$ caused $89 \pm 3 \%$ and $94 \pm 1 \%$ inhibition of ${ }^{1} \mathrm{O}_{2}$, respectively (Fig. 4b). Remaining samples (GA and IGA graft at other concentration) showed nonsignificant differences $(P>0.05)$ at any time of irradiation. As showed in Table 1, IGA graft exhibited a low capacity to inhibit ${ }^{1} \mathrm{O}_{2}$, about $18 \%$. In general, phenolic compounds have a reduced capacity to extinguish the ${ }^{1} \mathrm{O}_{2}$ radical. Wang and Jiao (2000) assessed the antioxidant activity of fruit juices rich in phenolic compounds and reported an inhibition of ${ }^{1} \mathrm{O}_{2}$ from 6.3 to $17.4 \%$. (Wang \& Jiao, 2000), several molecules have different antioxidant capacity to inhibit ${ }^{1} \mathrm{O}_{2}$, for example $\beta$ carotene (35.3\%), $\alpha$-tocopherol (22.5\%), glutatation (22.5\%), ascorbic acid (6.18\%) and chlorogenic acid (0.44\%).

The efficiency of the chemical reaction to scavenge ${ }^{1} \mathrm{O}_{2}$, depends on the presence of hydroxyl groups at the $C_{2}=C_{3}$ position of the flavonoids' C ring (Tournaire et al., 1993). Furthermore, when the hydroxyl group is glycosylated its capacity to scavenge ${ }^{1} \mathrm{O}_{2}$ decreases (Majer, Neugart, Krumbein, Schreiner, \& Hideg, 2014). In phenolic compounds and according to Tournaire et al. (1993), the absence of a carbonyl group in the $\mathrm{C}$ ring leads to a flat molecular structure, that is why catechin is the flavonoid with the highest efficiency to extinguish the ${ }^{1} \mathrm{O}_{2}$ radical $\left(5.8 \times 10^{6} \mathrm{~L} \mathrm{~mol}^{-1} \mathrm{~s}^{-1}\right)$. This may explain the significant capacity of GA and the low reducing power of IGA to scavenge ${ }^{1} \mathrm{O}_{2}$.

\subsubsection{Inhibition effect of lipid peroxidation}

Lipid peroxidation (LP) includes a series of chain reactions where a free radical will cause oxidation of unsaturated fatty acids and to produce a large number of degradation products

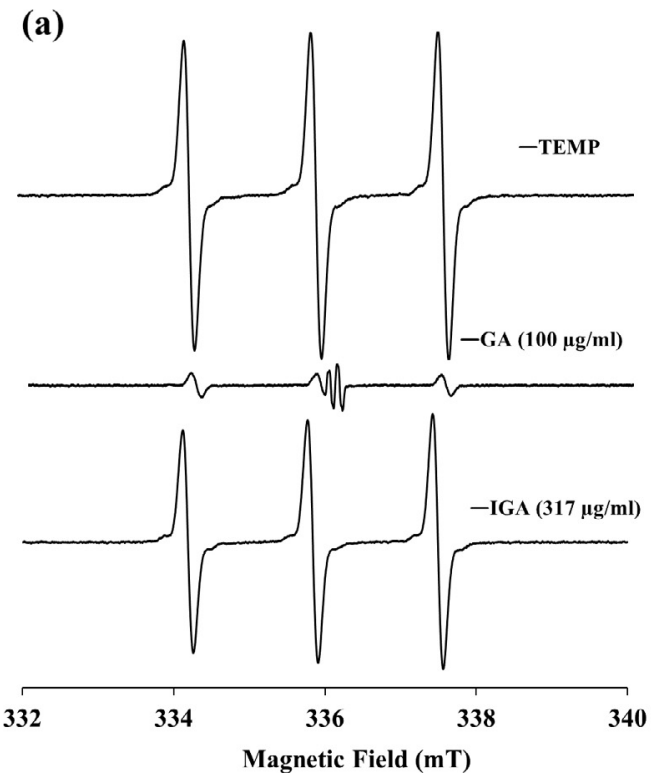

(b)

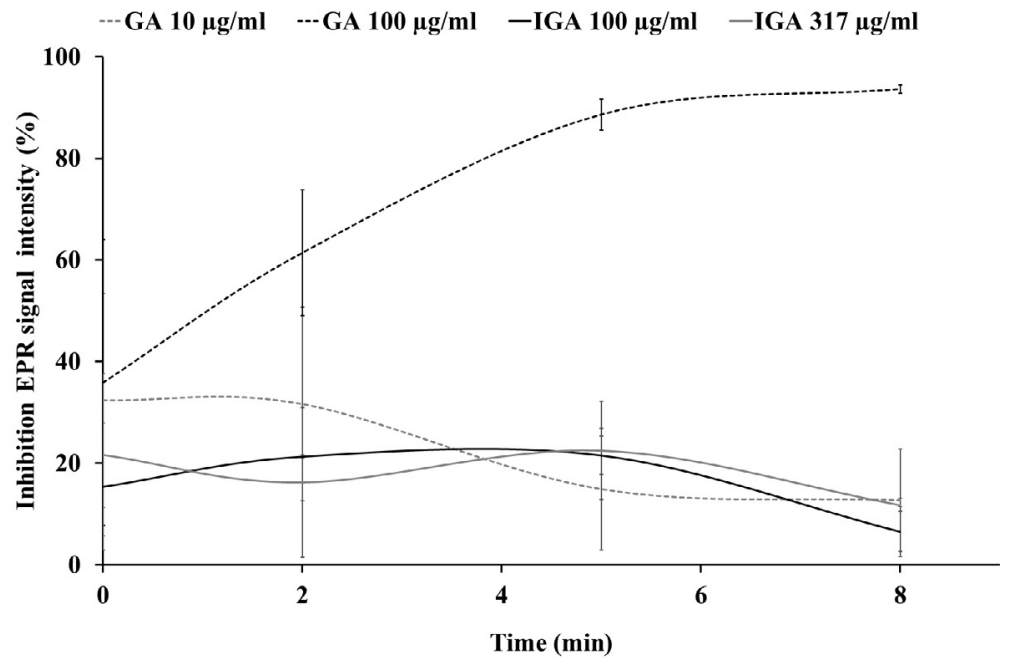

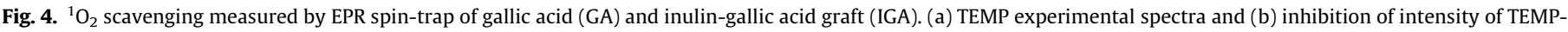
signal. 
$\left[\mathrm{LH}+\mathrm{R} . \rightarrow \mathrm{RH}+\mathrm{L} .+\mathrm{O}_{2} \rightarrow \mathrm{LOO} .+\mathrm{LH} \rightarrow \mathrm{L} .+\mathrm{LOOH}\right]$ (Abuja \& Albertini, 2001). The method to measure LP is based on the reaction of TBARS which yields some compounds formed in the course of the reaction. After reacting with TBA these compounds yield a pinkish red chromogen with the maximum absorbance at $540 \mathrm{~nm}$, whose concentration is related to the extent of lipid peroxidation. Fig. 5 shows the effect of IGA, inulin and GA on the production of TBARS where native inulin was used as a negative control. GA showed a significant effect $(p<0.05)$ on the inhibition of TBARS depending on its concentration $(100 \mu \mathrm{g} / \mathrm{mL})$ causing an inhibition of $92 \%$ (Table 1). IGA showed a significant effect only at a high concentration $(100 \mu \mathrm{g} / \mathrm{mL})$. Grafting polymers with some type of phenolic compounds increase their capacity to reduce LP, which depends on the number of grafted moieties in the polymer (Liu, Lu, Kan, Tang et al., 2013; Liu, Wen et al., 2014; Parisi et al., 2010). In the present study and according to Table 1 , the low capacity of IGA to inhibit LP $(19.6 \%$ at $100 \mu \mathrm{g} / \mathrm{mL})$ could be due to the low availability of the grafted gallic acid ( $16.3 \mathrm{mg} / \mathrm{g}$ inulin) either to steric hindrance caused by the substitution of hydroxyl groups in the structure of GA (Tournaire et al., 1993). Nevertheless, the increase in the grafted polymer concentration increases the antioxidant capacity of the medium (Liu, Lu, Kan, Jin et al., 2013).

\subsection{In vitro prebiotic effect of IGA}

Lactobacilli species have been commonly used as a model to evaluate the prebiotic capacity of fermentable sugars because these lactic acid bacteria, among other characteristics display an observable growth after about $15 \mathrm{~h}$ of incubation (Adebola et al., 2014; Corral et al., 2008). Fig. 6 shows the growth of Lactobacillus acidophilus in the presence of several carbon sources as a function of time: inulin (MRS-Inulin), IGA (MRS-IGA) and glucose (MRSGluc, positive control) where the higher growth was reached after $14 \mathrm{~h}$ of incubation. Furthermore, a trial was performed in the absence of carbon source (negative control) where no growth of the probiotic bacteria was observed. $\mathrm{pH}$ values were also determined and its change was considered as an indicator of the fermentative bacterial activity and as an evidence of the prebiotic effect of the inulin incorporated in the culture broth (Madhukumar \& Muralikrishna, 2010). In order to get some kinetic parameters summarizing the evolution of the optical density (OD)
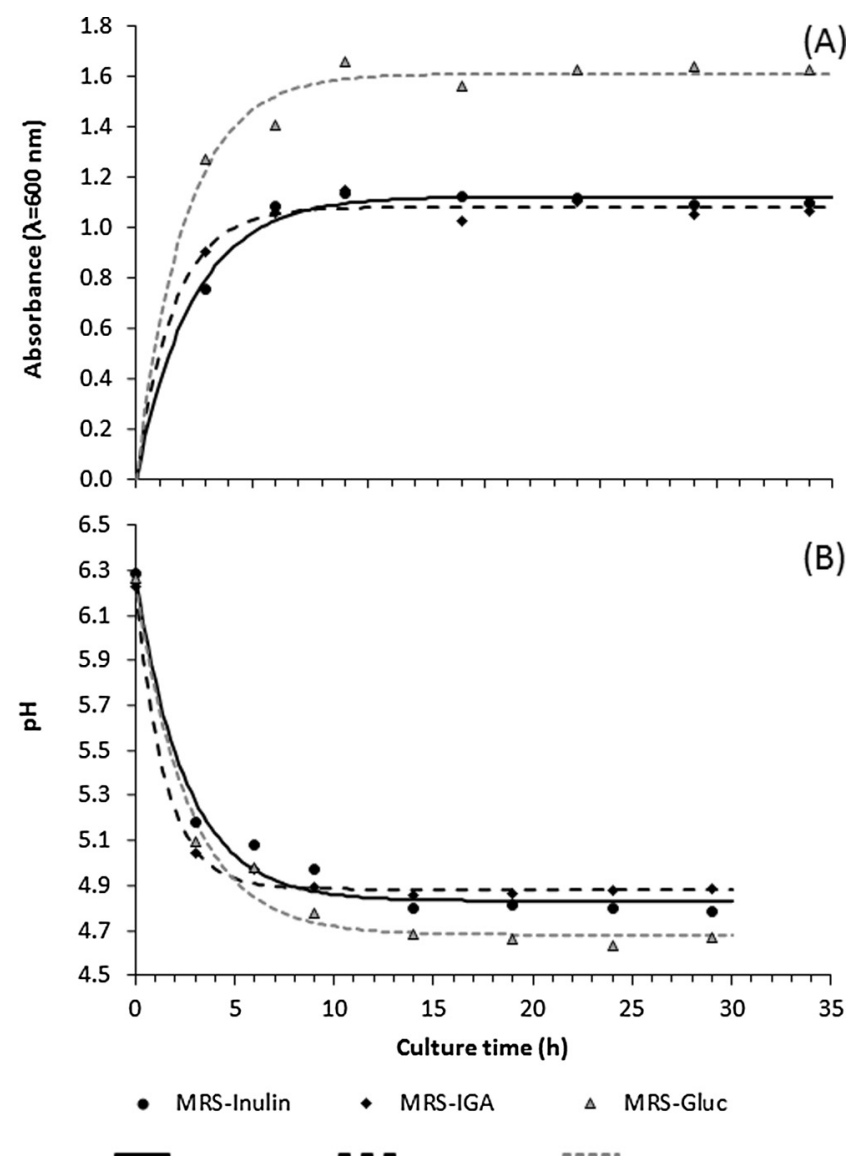

Fig. 6. Growth of Lactobacillus acidophilus expressed as $\mathrm{OD}_{600 \mathrm{~nm}}$ and $\mathrm{pH}$ decrease. Carbon source: native inulin (MRS-Inulin), inulin-gallic acid graft (MRS-IGA) and glucose (MRS-Gluc).

or the $\mathrm{pH}$ of the liquid medium from a time zero to a steady state, the observed data were correlated with a first order kinetic model (Eqs. (2) and (3)).

$\mathrm{OD}_{\mathrm{t}} / \mathrm{OD}_{\infty}=1-\operatorname{EXP}(-\mathrm{kt})$

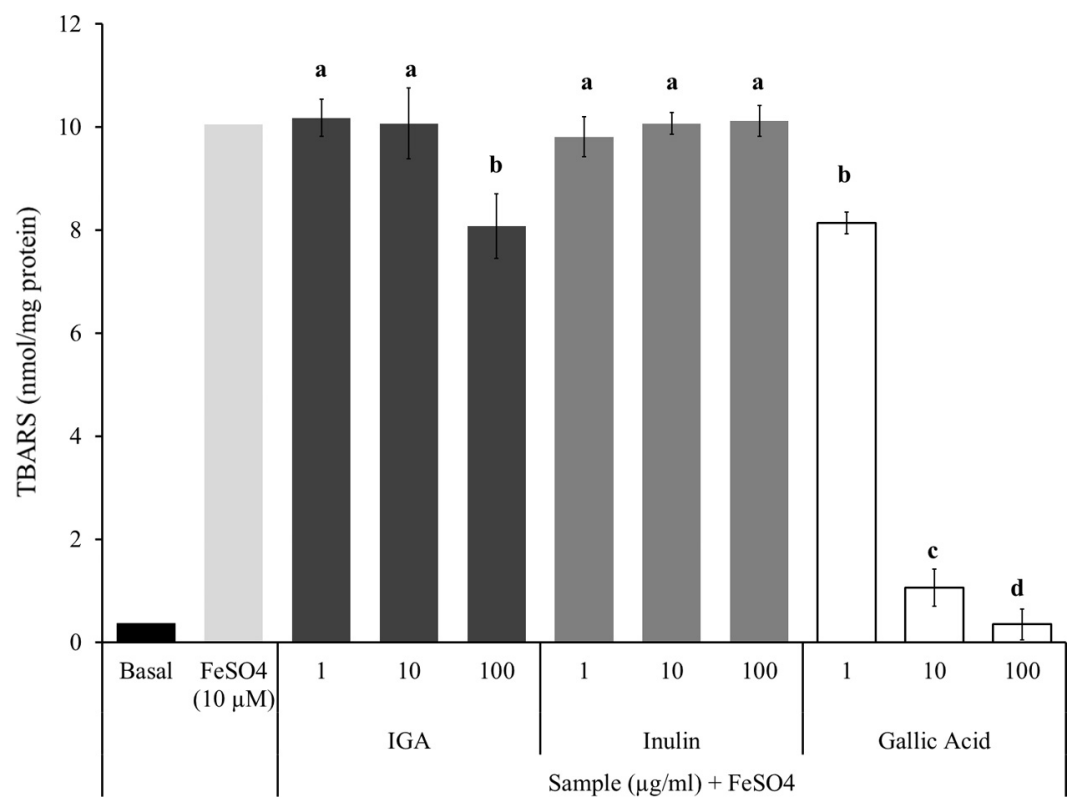

Fig. 5. Effect of inulin-gallic acid graft (IGA), inulin and gallic acid concentrations on TBARS formation. 
Table 3

Total phenolics by carbon source and means values after $14 \mathrm{~h}$ of L. acidophillus incubation.

\begin{tabular}{llll}
\hline Parameter & MRS-Inulin & MRS-IGA & MRS-Glucose \\
\hline Total phenolics $^{\mathrm{a}}$ & $0.43 \pm 0.320^{\mathrm{a}}$ & $16.30 \pm 0.420$ & $0.15 \pm 0.010$ \\
$\mathrm{OD}_{600 \mathrm{~nm}}$ at the steady state & $1.12 \pm 0.047 \mathrm{~B}^{\mathrm{b}}$ & $1.08 \pm 0.043 \mathrm{~B}$ & $1.61 \pm 0.077 \mathrm{~A}$ \\
$\mathrm{OD}_{600 \mathrm{~nm}}$ rate constant & $0.41 \pm 0.101 \mathrm{~A}$ & $0.62 \pm 0.206 \mathrm{~A}$ & $0.48 \pm 0.154 \mathrm{~A}$ \\
pH at the steady state & $4.83 \pm 0.105 \mathrm{~A}$ & $4.88 \pm 0.039 \mathrm{~A}$ & $4.68 \pm 0.097 \mathrm{~B}$ \\
pH rate constant & $0.39 \pm 0.169 \mathrm{~B}$ & $0.67 \pm 0.132 \mathrm{~A}$ & $0.37 \pm 0.183 \mathrm{~B}$
\end{tabular}

a Total phenolics reported as mg equivalents of gallic acid/g sample.

b Mean values $\pm 95 \%$ Confidence Limits. Values followed by different letters are significantly different at a $\mathrm{p}<0.05$.

$\mathrm{pH}_{\mathrm{t}} / \mathrm{pH}_{\infty}=\operatorname{EXP}(-\mathrm{kt})$

With this model, two parameter estimates were obtained and compared: a rate constant $(\mathrm{k})$, and a maximum value $\left(\mathrm{OD}_{\infty}\right.$ or $\mathrm{pH}_{\infty}$ ) considering that at infinite time, the variables reached their equilibrium state (Atkins, 1998, chap. 25). Hence, $\mathrm{OD}_{\mathrm{t}}$ or $\mathrm{pH}_{\mathrm{t}}$ represent OD or $\mathrm{pH}$ units at a time (in hours).

Table 3 shows the concentration of GA in the MRS-IGA medium (16.3 mg GAE/g), its lack in the MRS-Inulin and MRS-Glucose media, the rate constants and the values at the steady state. According to Fig. 6, the growth kinetics of Lactobacillus acidophilus responded adequately to the first order kinetic model shown in Eqs. (2) and (3), with coefficients of determination $\left(R^{2}\right)$ higher than 0.90 .

According to the obtained parameter estimates showed in Table 3, the rate constants related to the OD were statistically similar suggesting that the rate of bacterial growth was not affected by the carbon source. However, the rate of decrease of the $\mathrm{pH}$ in the liquid medium was greater in the presence of IGA which may have been caused by the release of gallic acid after consumption of the inulin fraction by the lactic acid bacteria. Besides, the higher bacterial growth was observed, as expected, in the MRS-Glucose medium because its $\mathrm{OD}_{600 \mathrm{~nm}}$ at the steady state was statistically higher than in the other media. In the same way, the $\mathrm{pH}$ at the steady state was the lowest. These results show that the presence of gallic acid grafted in the inulin chain did not affect the growth of the lactic acid bacteria.

The concentration of the carbon source is critical to evaluate the oligosaccharides prebiotic activity. Li, Kim, Jin, and Zhou (2008) reported that $1 \%$ of burdock inulin in the culture medium is an adequate concentration to confirm the growth of Bifidobacteria. Corral et al. (2008) used $2 \%$ chicory inulin and other fructans as carbon source in the growth of Lactobacillus strains. Generally, the growth of probiotic bacteria is higher when the sugar concentration is increased in the culture medium (Adebola et al., 2014; Yang et al., 2011). Incorporating any type of inulin in the culture media causes a long-term bifidogenic effect on probiotic bacteria which is accompanied by a decrease of $\mathrm{pH}$ owing to the production of acetic and lactic acid (López-Molina et al., 2005). The OD curves shown in Fig. 6 indicate no difference in the L. acidophilus growth modified by the carbon source consumed. However, the pronounced $\mathrm{pH}$ drop in the MRS-G medium appears to be an indicator of the increased production of lactic acid caused by L. acidophilus which is not reflected in the case of MRS-Inulin and MRS-IGA media. Growth of $L$. acidophilus is not influenced by the presence of gallic acid onto inulin, suggesting that there is not relationship between antioxidant activity and prebiotic activity (Yang et al., 2011).

\section{Conclusions}

Inulin does not show any antioxidant activity, but grafting gallic acid onto native inulin gives this dietary fibre a significant capacity to scavenge free radicals such as DPPH and ${ }^{1} \mathrm{O}_{2}$ and to reduce lipid peroxidation. Moreover, inulin shows a significant capacity to stimulate the growth of Lactobacillus acidophilus and gallic acid molecules grafted onto native inulin does not interfere with its prebiotic activity. This work shows that it is possible to provide radical-scavenging ability to the inulin-type fructooligosaccharides avoiding decrease of their prebiotic properties, which could extend its potential as functional foods.

\section{Acknowledgements}

The authors wish to thank the Consejo Nacional de Ciencia y Tecnología-México (CONACyT-México) for the scholarship granted to Daniel Arizmendi-Cotero (Grant number: 370573), the Centro Conjunto de Investigación en Química Sustentable UAEM-UNAM, Alejandra Nuñez Pineda, Virgínia Gómez-Vidales, Antonio NietoCamacho and Lizbeth Triana Cruz for their assistance in the characterization and analysis of the IR spectra.

\section{References}

Abuja, P. M., \& Albertini, R. (2001). Methods for monitoring oxidative stress, lipid peroxidation and oxidation resistance of lipoproteins. Clinica Chimica Acta, 306, $1-17$.

Adebola, O. O., Corcoran, O., \& Morgan, W. A. (2014). Synbiotics: The impact of potential prebiotics inulin, lactulose and lactobionic acid on the survival and growth of lactobacilli probiotics. Journal of Functional Foods, 10, 75-84.

Arizmendi-Cotero, D., Gómez-Espinosa, R. M., García, O. D., Gómez-Vidales, V., \& Dominguez-Lopez, A. (2016). Electron paramagnetic resonance study of hydrogen peroxide/ascorbic acid ratio as initiator redox pair in the inulingallic acid molecular grafting reaction. Carbohydrate Polymers, 136, 350-357.

Atkins, P. (1998). Physical-chemistry (6th ed). New York, NY: W. H. Freeman and Company.

Cho, Y.-S., Kim, S.-K., Ahn, C.-B., \& Je, J.-Y. (2011). Preparation, characterization, and antioxidant properties of gallic acid-grafted-chitosans. Carbohydrate Polymers, 83, 1617-1622.

Cirillo, G., Kraemer, K., Fuessel, S., Puoci, F., Curcio, M., Spizzirri, U. G., \& Iemma, F. (2010). Biological activity of a gallic acid-gelatin conjugate. Biomacromolecules, 11, 3309-3315.

Corral, M., Valdivieso-Ugarte, M., Ferna, L., Adrio, L., \& Velasco, J. (2008). Metabolism of prebiotic products containing $\mathrm{b}(2-1)$ fructan mixtures by two Lactobacillus strains. Anaerobe, 14, 184-189.

Curcio, M., Puoci, F., Iemma, F., Parisi, O. I., Cirillo, G., Spizzirri, U. G., \& Picci, N. (2009). Covalent insertion of antioxidant molecules on chitosan by a free radical grafting procedure. Journal of Agricultural and Food Chemistry, 57, 5933-5938.

Gómez-Vidales, V., Granados-Oliveros, G., Nieto-Camacho, A., Reyes-Solís, M., \& Jiménez-Estrada, M. (2014). Cacalol and cacalol acetate as photoproducers of singlet oxygen and as free radical scavengers, evaluated by EPR spectroscopy and TBARS. Royal Society of Chemistry, 4, 1371-1377.

Granados-Oliveros, G., Gómez-Vidales, V., Nieto-Camacho, A., Morales-Serna, J. A., Cárdenas, J., \& Salmón, M. (2013). Photoproduction of H2O2 and hydroxyl radicals catalysed by natural and super acid-modified montmorillonite and its oxidative role in the peroxidation of lipids. RSC Advances, 3, 937-944.

Grube, M., Bekers, M., Upite, D., \& Kaminska, E. (2002). Infrared spectra of some fructans. Spectroscopy, 16, 289-296.

Je, J.-Y., Park, P.-J., \& Kim, S.-K. (2004). Radical scavenging activity of heterochitooligosaccharides. European Food Research and Technology, 219, 60-65.

Li, D., Kim, J. M., Jin, Z., \& Zhou, J. (2008). Prebiotic effectiveness of inulin extracted from edible burdock. Anaerobe, 14, 29-34.

Liu, J., Lu, J., Kan, J., \& Jin, C. (2013). Synthesis of chitosan-gallic acid conjugate: Structure characterization and in vitro anti-diabetic potential. International Journal of Biological Macromolecules, 62, 321-329.

Liu, J., Lu, J., Kan, J., Tang, Y., \& Jin, C. (2013). Preparation, characterization and antioxidant activity of phenolic acids grafted carboxymethyl chitosan. International Journal of Biological Macromolecules, 62, 85-93.

Liu, J., Lu, J., Kan, J., Wen, X., \& Jin, C. (2014). Synthesis, characterization and in vitro anti-diabetic activity of catechin grafted inulin. International Journal of Biological Macromolecules, 64, 76-83.

Liu, J., Wen, X. Lu, J., Kan, J. \& Jin, C. (2014). Free radical mediated grafting of chitosan with caffeic and ferulic acids: Structures and antioxidant activity. International Journal of Biological Macromolecules, 65, 97-106.

López-Molina, D., Navarro-Martínez, M. D., Melgarejo, F. R., Hiner, a. N. P., Chazarra, S., \& Rodríguez-López, J. N. (2005). Molecular properties and prebiotic effect of inulin obtained from artichoke (Cynara scolymus L.). Phytochemistry, 66, 1476-1484.

Madhukumar, M. S., \& Muralikrishna, G. (2010). Structural characterisation and determination of prebiotic activity of purified xylo-oligosaccharides obtained from Bengal gram husk (Cicer arietinum L.) and wheat bran (Triticum aestivum). Food Chemistry, 118, 215-223.

Majer, P., Neugart, S., Krumbein, A., Schreiner, M., \& Hideg, E. (2014). Singlet oxygen scavenging by leaf flavonoids contributes to sunlight acclimation in Tilia platyphyllos. Environmental and Experimental Botany, 100, 1-9. 
Mercado-Mercado, G., Blancas-Benitez, F. J., Velderrain-Rodríguez, G. R., MontalvoGonzález, E., González-Aguilar, G. A., Alvarez-Parrilla, E., \& Sáyago-Ayerdi, S. G. (2015). Bioaccessibility of polyphenols released and associated to dietary fibre in calyces and decoction residues of Roselle (Hibiscus sabdariffa L.). Journal of Functional Foods, 18, 171-181.

Parisi, O. I., Puoci, F., Iemma, F., De Luca, G., Curcio, M., Cirillo, G., ... Picci, N. (2010). Antioxidant and spectroscopic studies of crosslinked polymers synthesized by grafting polymerization of ferulic acid. Polymers for Advanced Technologies, 21 774-779.

Park, P.-J., Je, J.-Y., \& Kim, S.-K. (2003). Free radical scavenging activity of chitooligosaccharides by electron spin resonance spectrometry. Journal of Agricultural and Food Chemistry, 51, 4624-4627.

Pasanphan, W., Buettner, G. R., \& Chirachanchai, S. (2010). Chitosan gallate as a novel potential polysaccharide antioxidant: An EPR study. Carbohydrate Research, 345, 132-140.

Pasanphan, W., \& Chirachanchai, S. (2008). Conjugation of gallic acid onto chitosan: An approach for green and water-based antioxidant. Carbohydrate Polymers, 72, 169-177.

Rubel, I. A., Pérez, E. E., Genovese, D. B. \& Manrique, G. D. (2014). In vitro prebiotic activity of inulin-rich carbohydrates extracted from Jerusalem artichoke (Helianthus tuberosus L.) tubers at different storage times by Lactobacillus paracasei. Food Research International, 62, 59-65.

Saura-Calixto, F. (2011). Dietary fiber as a carrier of dietary antioxidants: An essential physiological function. Journal of Agricultural and Food Chemistry, 59, 43-49.

Saura-Calixto, F. Pérez-Jiménez, J. \& Goñi, I. (2009). Contribution of cereals to dietary fibre and antioxidant intakes: Toward more reliable methodology. Journal of Cereal Science, 50, 291-294.

Spizzirri, U. G., Altimari, I., Puoci, F., Parisi, O. I., Iemma, F., \& Picci, N. (2011). Innovative antioxidant thermo-responsive hydrogels by radical grafting of catechin on inulin chain. Carbohydrate Polymers, 84, 517-523.
Spizzirri, U. G., Iemma, F., Puoci, F., Cirillo, G., Curcio, M., Parisi, O. I., \& Picci, N. (2009). Synthesis of antioxidant polymers by grafting of gallic acid and catechin on gelatin. Biomacromolecules, 10, 1923-1930.

Spizzirri, U. G., Parisi, O. I., Iemma, F., Cirillo, G., Puoci, F., Curcio, M., \& Picci, N. (2010). Antioxidant-polysaccharide conjugates for food application by ecofriendly grafting procedure. Carbohydrate Polymers, 79, 333-340.

Toti, U. S., \& Aminabhavi, T. M. (2004). Synthesis and characterization of polyacrylamide grafted sodium alginate membranes for pervaporation separation of water + isopropanol mixtures. Journal of Applied Polymer Science, 92, 2030-2037.

Tournaire, C., Croux, S., Maurette, M. T., Beck, I., Hocquaux, M., Braun, A. M., \& Oliveros, E. (1993). Antioxidant activity of flavonoids: Efficiency of singlet oxygen $(1 \Delta \mathrm{g})$ quenching. Journal of Photochemistry and Photobiology, B: Biology, $19,205-215$.

Wang, S. Y., \& Jiao, H. (2000). Scavenging capacity of berry crops on superoxide radicals, hydrogen peroxide, hydroxyl radical's, and singlet oxygen. Journal of Agricultural and Food Chemistry, 48, 5677-5684.

Woranuch, S., Yoksan, R., \& Akashi, M. (2015). Ferulic acid-coupled chitosan: Thermal stability and utilization as an antioxidant for biodegradable active packaging film. Carbohydrate Polymers, 115, 744-751.

Yang, B., Prasad, K. N., Xie, H., Lin, S., \& Jiang, Y. (2011). Structural characteristics of oligosaccharides from soy sauce lees and their potential prebiotic effect on lactic acid bacteria. Food Chemistry, 126, 590-594.

Zhang, X., Geng, X., Jiang, H., Li, J., \& Huang, J. (2012). Synthesis and characteristics of chitin and chitosan with the (2-hydroxy-3-trimethylammonium) propyl functionality, and evaluation of their antioxidant activity in vitro. Carbohydrate Polymers, 89, 486-491.

Zhong, K., Lin, W., Wang, Q., \& Zhou, S. (2012). Extraction and radicals scavenging activity of polysaccharides with microwave extraction from mung bean hulls International Journal of Biological Macromolecules, 51, 612-617. 